\title{
Erratum to: Smart City Implementation
}

\section{Erratum to: \\ R.P. Dameri, Smart City Implementation, Progress in IS, DOI 10.1007/978-3-319-45766-6}

The original version of the book was inadvertently published without co-author affiliation in Chapter 5 and Preface text "...implementations, Chap. 5 regards..." and it should be changed to "...implementations, Chap. 5 written with co-author Clara Benevolo". The erratum chapter and the book have been updated with the changes.

The updated original online version for this chapter can be found at DOI 10.1007/978-3-319-45766-6_5

DOI 10.1007/978-3-319-45766-6

R.P. Dameri ( $\bowtie)$

Dipartimento di Economia, University of Genoa, Genoa, Italy

e-mail: dameri@economia.unige.it 